ing large numbers of hypertensive patients for long periods during the past ten years with a variety of drugs and does not recollect having any other cases of polyarteritis supervene during their management. Moreover, since these three cases have been made known two other possible cases of collagen disease attributable to guanethidine have been brought to our notice. In one case, belonging to Dr. A. R. Horler (personal communication, 1963), fever, polyarthritis, and polyneuritis followed treatment of hypertension with guanethidine, pempidine, and chlorothiazide. In the other, reported to us by Professor J. T. Ingram (personal communication, 1963), disseminated lupus erythematosus developed in a patient taking guanethidine and digoxin. It is not claimed, however, that the case for a causal relationship has been established with certainty. But in view of its potential importance it has been thought wise to present the facts. The possibility of chlorothiazide as a causal agent has also been considered, since it too was being taken with guanethidine in one of the cases and possibly in two of them; but it is so widely used for other purposes without harm accruing that this seems unlikely. As to the possible significance of the combination of guanethidine and chlorothiazide, no evidence is offered. It could apply to only two of the cases here presented.

\section{Summary}

Three cases are described in which " collagen vascular disease" developed during treatment of long-standing hypertension with guanethidine.
They presented as mononeuritis multiplex, polyarteritis nodosa, and cerebral vasculitis respectively.

A possible causal relationship with guanethidine is discussed.

Our thanks are due to Professor A. G. Heppleston for the biopsy report on Case 1 ; to Dr. A. R. Horler and Professor J. T. Ingram for permission to quote their two other cases of possible sensitivity ; and to Dr. J. N. Walton for his neurological opinion upon Case 3.

\section{REFERENCES}

Dalgleish, P. G. (1952). Lancet, 2, 319.

Edge, J. R., Fazlullah, S., and Ward, J. (1955). Ibid., 1, 1153.

Hill, W. R., and Damiani, C. R. (1946). New Engl. f. Med., 235, 897.

Hodge, P. R., and Lawrence, J. R. (1957). Med. F. Aust., 1, 640.

Knowles, H. C., Zeek, P. M., and Blankenhorn, M. A. (1953). Arch. intern. Med., 92, 789.

Lichtenstein, L., and Fox, L. J. (1946). Amer. F. Path., 22, 665.

McCormick, R. V. (1950). f. Amer. med. Ass., 144, 1453.

Meyler, L., Stoel, L., Hogewind, F., Kooy, A. N. F., and Loonstra, Ti. (1960). Acta med. scand., 167, 95.

Miller, H. G., and Daley, R. (1946). Quart. F. Med., 15, 255.

Rasmussen, H. (1955). F. Allergy, 26, 394.

Rose, G. A., and Spencer, H. (1957). Quart. 7. Med., 26, 43.

Slocumb, C. H., Polley, H. F., and Ward, L. E. (1957). Proc. Mayo Clin., 32, 227.

Symmers, W. St. C. (1958). Symposium C.I.O.M.S. Scientific Publ. Oxford, p. 209.

- (1962). Proc. roy. Soc. Med., 55, 20.

Van Wyk, J. J., and Hoffman, C. R. (1948). Arch. intern. Med., 81, 605.

Waugh, D. (1952). Amer. F. Path., 28, 437.

Winton, S. S., and Nora, E. D. (1955). Amer. F. Med., 18, 66.

\title{
Recovery from Presumed Subacute Inclusion-body Encephalitis
}

\author{
J. M. S. PEARCE, ${ }^{+} \dagger$ M.B., M.R.C.P. ; D. D. BARWICK, ${ }^{*}$ M.B., M.R.C.P.ED.
}

Brit. med. 7., 1964, 2, 611-613

Subacute inclusion-body encephalitis was first reported by Dawson (1934) as a disease of children characterized by the finding of type $A$ inclusions in the nuclei of cortical neurones. Similar cases were subsequently described (van Bogaert, 1945 ; van Bogaert et al., 1956) under the title of "subacute sclerosing leucoencephalitis," and it is now believed that these two syndromes are identical (Greenfield, 1950). The disease affects children and young adults and has an insidious afebrile onset, usually with deterioration of personality and behaviour and sometimes associated with epilepsy. The second stage is characterized by akinetic mutism with complex involuntary movements, myoclonic or ballistic, occurring at intervals of 5-10 seconds and accompanied by synchronous periodic highvoltage complexes followed by periods of electrical silence in the electroencephalogram (E.E.G.). The third and final stage is one of progressive decortication leading to death within months or at the most two years. Excellent reviews of the clinicopathological findings are given by Dawson (1934), van Bogaert et al. (1956), Foley and Williams (1953), Pallis and

\footnotetext{
- Department of Neurology, Regional Neurological Centre, General Hospital, Newcastle upon Tyne.

† Present address: Senior Registrar, Department of Neurology, the General Infirmary at Leeds.
}

Spillane (1957), Poser and Radermecker (1959), and by Brain et al. (1948).

Remissions are occasionally seen in the early stages (Simpson, 1961), but recovery is so rare that in Simpson's Case 11, when apparent recovery occurred, he concluded that the diagnosis was incorrect. One non-fatal case was recorded by Kurtzke (1956), who accepted the diagnosis.

We report below a patient who was believed to be suffering from this condition but who has apparently made a complete recovery.

\section{Case Report}

A 17-year-old boy was sent home from school on 14 June 1963 complaining of tiredness, loss of appetite, and a sore throat. He developed a generalized headache and drowsiness, and in the next few days exhibited severe behaviour disturbances, notably swearing, saying and doing inappropriate things, and being restless and totally disorientated. These symptoms led to his admission to a psychiatric unit, where physical examination disclosed no neurological signs, but an E.E.G. showed a doubtful focus in the right posterior temporal region. On 22 June, after an injection of methedrine, he had a major epileptic seizure followed by status epilepticus, which was controlled with paraldehyde and barbiturates. 
He was transferred to the Regional Neurological Centre on 26 June, where he was found to have no abnormal neurological signs but was dehydrated and exhibited mild neck-stiffness. He was confused and disorientated and his behaviour was bizarre, inappropriate, and totally disinhibited. After rehydration he was investigated with the following results.

\section{Investigations}

Haemoglobin 16 g./100 ml. ; white blood cells, 17,700/c.mm.; E.S.R., $10 \mathrm{~mm}$. in one hour; no abnormal cells seen. Serum sodium 143, potassium 3.6 , chloride $98 \mathrm{mEq} / 1$; $\mathrm{CO}_{2}$-combining power, $20 \mathrm{mEq} / \mathrm{l}$. Blood urea, $62 \mathrm{mg} . / 100 \mathrm{ml}$. Blood sugar two hours after food, $110 \mathrm{mg} . / 100 \mathrm{ml}$. Radiographs of skull and chest, normal. Bilateral carotid angiography showed no abnormality. Complement fixation tests were of insignificant titre (less than 1/8) in convalescent serum, to the following viruses: lymphocytic choriomeningitis, mumps, and polio viruses types 1,2 , and 3 .

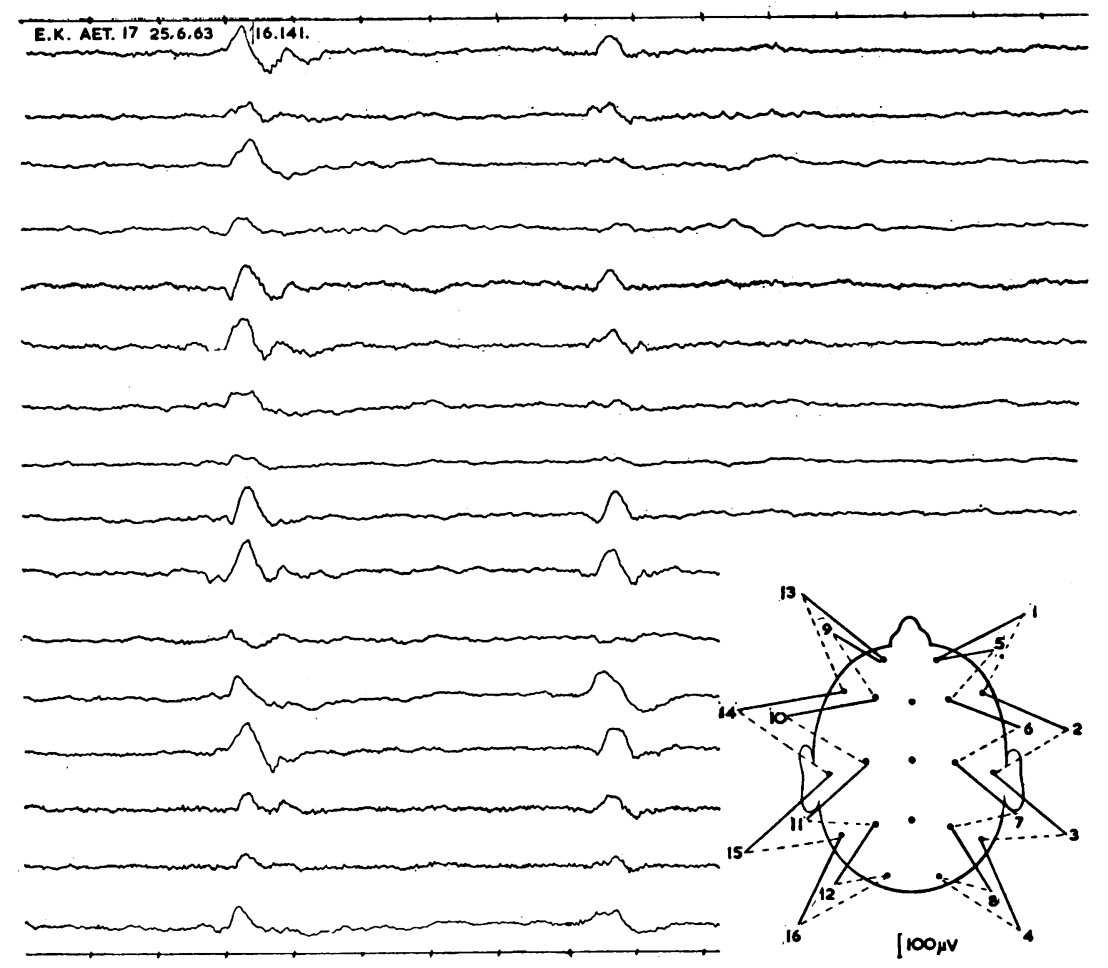

FIG. 1.-First E.E.G. record, showing repetitive complexes in some respects resembling altered $\mathrm{K}$ complexes.
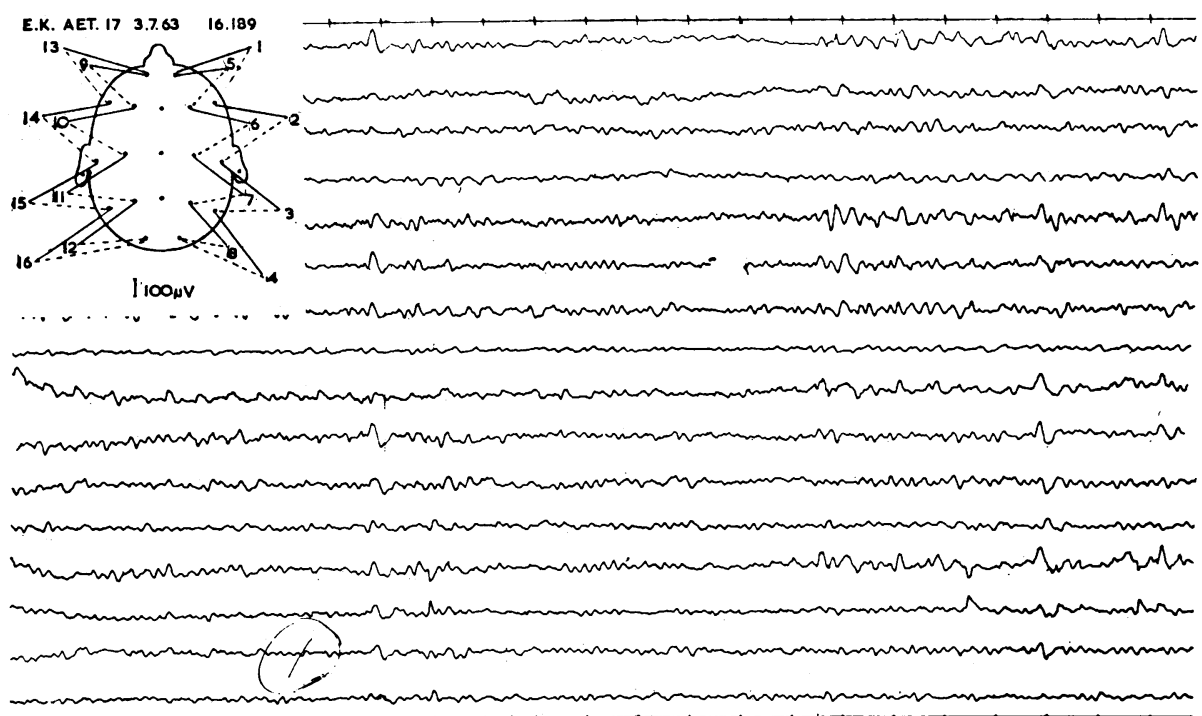

Fig. 2.-E.E.G. record taken nine days later, greatly improved and not suggestive of subacute inclusion-body encephalitis.
Cerebrospinal Fluid.-Cells: 40 c.mm. (polymorphs $88 \%$, lymphocytes $12 \%$ ). Protein, $128 \mathrm{mg} . / 100 \mathrm{ml}$.; gamma-globulin, $18 \%$ of total protein. Microscopy and culture (including acid-fast bacilli), negative.

\section{E.E.G. Studies}

The first record taken in the Regional Neurological Centre (Fig. 1) showed repetitive complexes which in some respects resembled altered $\mathrm{K}$ complexes. These outbursts were synchronous in all channels, but their morphology varied considerably from However, the recording from any one pair of electrodes revealed that the paroxysms had a remarkably constant form which remained fairly stable throughout the record. The discharges, which recurred at regular intervals throughout the record, were separated by periods of relative suppression, only a little irregular low-voltage slow activity being present.

It was felt that this record contained a sufficient number of the features found in subacute encephalitis (Radermecker and Poser, 1960) to be very strongly suggestive of this condition. The doubtful right-sided focus seen in the E.E.G. taken previously was not felt to invalidate this diagnosis, as such focal abnormalities have been seen in the condition under discussion.

A second record (Fig. 2), taken nine days later, was greatly improved and was in no way suggestive of subacute inclusion-body encephalitis. Since the disappearance of the typical complexes is not uncommon in the early stages of the disease, it was still felt that the prognosis was poor.

A follow-up record taken six months later was, however, virtually normal, showing no more than a slight immaturity.

The clinical picture, C.S.F. findings, and E.E.G. studies were highly suggestive of encephalitis of the subacute inclusion-body type. In view of the unlikely but treatable possibility of a para-infectious encephalitis he was treated with corticotrophin 40 units daily without obvious effect. One week after admission he developed polydipsia and polyuria with a daily intake of 6.51 . and a urinary output of 4.51 . of fluid. Careful fluid-balance studies were impossible because of the patient's psychiatric state, which rendered him uncooperative and incontinent; fluid deprivation was possible for eight hours, during which period the urinary specific gravity remained at 1002 . The daily urine volume was reduced to 2-3 1. after injections of 7.5 units of pitressin tannate in oil.

He was transferred to a psychiatric unit after the investigations were completed, and it was considered that he would deteriorate progressively. However, in the next few weeks he improved steadily, his E.E.G. returned to normal, and it became possible to withdraw the pitressin without return of the polyuria. Follow-up examinations nine months after the onset of this illness revealed neither psychiatric nor neurological abnormality.

\section{Discussion}

Proof of a diagnosis of a subacute inclusion-body encephalitis rests upon the characteristic pathological findings at necropsy or on brain biopsy. The diagnosis in life depends upon the occurrence of (1) the clinical features and their progression ; (2) a "paretic" Lange curve in the cerebrospinal fluid ; (3) the characteristic E.E.G. pattern; (4) the presence of nuclear inclusion bodies and degeneration of cortical ganglion cells in a brain biopsy. 
In many cases brain biopsy is not performed if the other features are present. The association of high-voltage synchronous complexes recurring at regular intervals over a long period of time, and separated by periods of relative electrical silence associated with involuntary movements, enables a diagnosis to be made with confidence (Cobb and Hill, 1950; Radermecker and Poser, 1960), but similar phenomena have been reported in encephalitis due to other causes (Lesse et al., 1958 ; Hoefer et al., 1959) and in head injury (Zappoli, 1959).

In the present case it seems probable that the encephalitis was of the subacute inclusion-body type but that he eventually recovered. The alternative explanation is that the patient suffered from another variety of subacute polioclastic encephalitis, but exhibited an E.E.G. record identical to that seen in inclusion-body encephalitis. The former explanation is favoured in this patient, particularly as recovery has been observed occasionally in similar cases (Kurtzke, 1956 ; Simpson, 1961).

The completeness of the recovery and the reversal of the abnormal E.E.G. pattern make it unlikely that relapse will occur, because the remissions observed in the early phases of the disease are usually incomplete, the patient remaining with a significant psychiatric and neurological disability.

A further point of interest in this patient is the transient occurrence of polyuria. Unfortunately his lack of co-operation made it impossible to carry out tests to prove the presence of diabetes insipidus, but the low specific gravity of the urine after fluid deprivation and the reversibility with vasopressin suggested this diagnosis rather than that of compulsive waterdrinking. It is therefore probable that there was involvement of the neurohypophysis or of the pituitary stalk by the encephalitic process in this case. This corresponds with the pathological observations of van Bogaert (1945), who found extensive subcortical involvement of white and to a less extent of grey matter.

\section{Summary}

A patient is described who was probably suffering from subacute inclusion-body encephalitis but who made an apparently complete recovery. This occurrence, and the unusual development of polyuria in this patient, are discussed in the light of previous knowledge of the disease.

We are indebted to Dr. J. N. Walton for his encouragement and kind permission to publish the details of this case.

\section{RBFBRENCES}

Bogaert, L. van (1945). 7. Neurol. Psychiat., 8, 101.

Radermecker, J, and Thiry, S. (1956), Rev. neurol, 95, 185. Brain, W. R., Greenfield, J. G., and Russell, D. S. (1948). Brain, 71,

Cobb, W. ., and Hill. D. (1950). Ibid., 73, 392

Dawson, J. R. (1934). Arch. Neural. Psychiat. (Chic.), 31, 685.

Foley, J., and Williams, D. (1953). Quart. F. Med., 22, 157.

Greenfield. J. G. (1950). Brain, 73, 141.

Hoefer, P. F. A., Lesse, S., and Austin, J. H. (1959). Proceedings of the First International Congress of Neurological Science, 3, 232.

Kurtzke, J. F. (1956). Neurology (Minneap.), 6, 371.

Lesse, S., Hoefer, P. F. A., and Austin, I. H. (1958). Arch. Neurol. Psychiat., 79, 359.

Pallis, C. A., and Spillane, J. D. (1957). Quart. J. Med., 26, 349.

Poser, C. M., and Radermecker, J. (1957). 9. Paediat., 50, 408. Radermecker, J., and Poser. C. M. (1960). Wld Neurol., 1, 422. Simpson, J. A. (1961). Lancet, 2, 685.

Zappoli, R. (1959). Electroenceph. clin. Neurophysiol., 11, 571.

\title{
Solitary Pyogenic Liver Abscess
}

\author{
JAMES S. DAVIDSON,* F.R.C.S.ED.
}

An extensive literature exists concerning solitary pyogenic abscess of the liver. It is not the purpose of this paper to reiterate the main features of this condition but merely to comment on its aetiology. The single pyogenic liver abscess differs from multiple liver abscesses in that its cause often remains obscure (Ochsner et al., 1938). In one large series of 24 cases the cause was determined with certainty in only two (Rothenberg and Linder, 1934). An obscure aetiology has come to be accepted as a feature of single pyogenic liver abscess, and it is perhaps unfortunate that the word "cryptogenic" has come to be associated with the condition.

It is our experience that, though such abscesses may initially be cryptogenic, the cause not infrequently becomes apparent if the patients are investigated and followed up after surgical cure of the abscess.

During 1958-63 six patients with solitary pyogenic liver abscesses were scen in the thoracic surgical department of the Bradford Royal Infirmary. All were initially cryptogenic. The following case records relate to four of these patients in whom the probable cause of the abscess was eventually discovered. One patient in whom the cause remains unknown is still under observation. Another patient, a vagrant, has been lost sight of. None of the patients had been exposed to the risk of amoebic infection.

* Consultnnt Thoracic Surgeon, Bradford Royal Infirmary.

\section{Case 1}

A woman aged 62 was admitted to hospital on 21 October 1958 mentally confused, dyspnoeic, and cyanosed. One month previously she had developed a dry cough, malaise, and anorexia, followed later by rigors and increasing dyspnoea. She was treated at home with sulphonamides, penicillin, and tetracycline. On admission there was dullness on percussion at the right base, with coarse crepitations at both bases. W.B.C. count was $20,000 /$ c.m. ; haemoglobin $65 \%$; serum bilirubin $0.8 \mathrm{mg} .100 \mathrm{ml}$; serum alkaline phosphatase 21.8 K.A. units ; total serum protein $5.1 \mathrm{~g} . / 100 \mathrm{ml}$. $\mathrm{X}$-ray examination showed elevation and immobility of the right dome of the diaphragm, congestive changes at the bases of both lungs, and a small pleural effusion on the right side. An erroneous diagnosis of subphrenic abscess was made.

The subphrenic space was approached through the bed of the eleventh rib. No subphrenic abscess was found. The surface of the liver looked normal, but on palpation an area of abnormal consistency was felt in the upper and posterior part of the right lobe of the liver. An exploring needle encountered pus $1 \frac{1}{2}$ in. $(3.8 \mathrm{~cm}$.) from the liver surface. An abscess containing $10 \mathrm{oz}$. $(285 \mathrm{ml}$.) of foul-smelling pus was opened and drained. The pus proved to be sterile on aerobic and anaerobic culture. The patient's subsequent improvement was rapid.

After recovery a barium-meal examination showed a large penetrating ulcer on the middle of the lesser curvature of the stomach. She admitted to no symptoms of peptic ulcer either at the time of $x$-ray examination or in the past. Follow-up over a year showed 